\title{
Advertising and the rise of the free daily
}

J.J. Gabszewicz, D. Laussel and N. Sonnac

Discussion Paper 2006-45

\section{Département des Sciences Économiques de l'Université catholique de Louvain}




\title{
CORE Discussion Paper 2006/87
}

\author{
Advertising and the rise of the free daily \\ newspapers \\ Jean J. Gabszewicz \\ CORE, Université Catholique de Louvain \\ Didier Laussel \\ GREQAM, Aix-Marseille Université \\ Nathalie Sonnac \\ CREST-LEI, Université de Paris 2
}

October 12, 2006

\begin{abstract}
We analyze the competition between two newspapers in a vertical differentiation model where the qualities of the journals are determined endogenously in the first stage of the game. We show that when the advertising revenues per reader increase there is a critical value above which the quality of the low quality newspaper discontinuously falls while it becomes similtaneously a free newspaper. This is beneficial to the high quality journal and detrimental to the readers.
\end{abstract}

JEL Classification: L150, L820

Keywords: Advertising, Newspapers quality 


\section{Introduction}

In this paper we provide a theoretical explanation for the uprise of the free newspapers' press which is based on the expansion of advertising revenues. A now large and bulking literature has analyzed the influence of growing advertising revenues on media content and, more specifically, on newspapers' content (see for instance Anderson and Coate (2006), Gabszewicz, Laussel and Sonnac $((2001),(2002)$, Dukes and Gal-Or (2003)). However there is another remarkable, though rather new ${ }^{1}$, feature in the development of the daily press industry, namely the emerging uprise of several free newspapers (such as "Metro" or "20 minutes" in eleven European countries). Presently, free daily newspapers exist in 38 countries and 23 million copies are read by at least 45 million people daily. In spite of this impressive uprise, traditional no free newspapers still do cohabit with the press which is sold for free. To the best of our knowledge, these features have not yet attracted the attention of theoretical scholars. In particular, no analysis seems available so far which would provide an explanation for the development of free newspapers, as well as the simultaneous survival of the traditional daily press. In this note we provide a tentative explanation of this phenomena which is based on the idea that traditional newspapers are perceived by the readership as being of higher quality than those afforded by the daily press distributed for free to the readers. It is of course difficult to define an objective criterion in order to rank daily newspapers by their intrinsic quality. Furthermore, newspapers' characteristics are so numerous that reducing quality to a one-dimensional criterion seems hazardous. Moreover, daily newspapers are generally horizontally differentiated according to their position in the political spectrum. Nonetheless, it seems a reasonable approximation to assume that all readers would consider that free and no free daily newspapers can be qualitatively ranked, the latter being of higher quality than the former. The advantage of this simplification is that it allows us to analyze competition between traditional and free newspapers in a standard simple vertical differentiation two-stage game ${ }^{2}$ in which advertising revenues are taken into account, and in which newspapers' editors choose the quality levels of their outlet. However, contrary to several recent papers, in which the advertising market is explicitly described and the revenue per reader endogenously determined, we view here the advertising revenues per reader as exogenously given. Here we derive the game equilibrium as a function of the advertising revenues per reader. Our main finding is that, when advertising revenues expand beyond some level, the lowquality newspaper's editor decides a sudden drop both in the quality level of his outlet and of its price: he starts to provide it for free to the readership! This gives an endogenous explanation for the existence of free newspapers. Moreover, in spite of this apparently predatory behavior, the low quality editor does not evict at equilibrium his rival who sells the traditional newspaper at a positive

\footnotetext{
${ }^{1}$ In France the phenomenon appeared in 2002.

${ }^{2}$ see for instance Gabszewicz and Thisse (1979).
} 
price. On the contrary, in our model, this leads to an increase in the total revenue of the latter !

\section{The Model}

We assume that there are two competing newspapers $i=1,2$, which operate in two interrelated markets: the readers' and the advertisers' markets. In the readers' market they differ only by their qualities $q_{1}$ and $q_{2}, q_{i} \in[0,1]$, and their prices $p_{1}$ and $p_{2}$. In our interpretation newspaper 1 corresponds to the "traditional" newspaper. We assume the readership is neutral with respect to advertising $^{3}$. They differ in their degree $\theta$ of preference intensity for quality. A typical type $\theta$-reader derives a surplus $\theta q-p$ from buying at price $p$ a newspaper of quality $q$ and a surplus 0 when refraining to read any newspaper ${ }^{4}$. Under our assumptions readers single-home: they never buy the two newspapers simultaneously. Given readers' ad-neutrality, we may suppose without loss of generality that each newspaper derives a constant profit $s$ per reader from selling ads to advertisers ${ }^{5}$.

We consider a two-stage game in which the newspapers' editors first choose their qualities and then their prices. Assuming that $q_{1}>q_{2}$, demands $D_{i}$, $i=1,2$, to the firms obtain as

$$
\begin{aligned}
D_{1}\left(p_{1}, p_{2}, q_{1}, q_{2}\right) & =1-\frac{p_{1}-p_{2}}{q_{1}-q_{2}} \\
D_{2}\left(p_{1}, p_{2}, q_{1}, q_{2}\right) & =\frac{p_{1}-p_{2}}{q_{1}-q_{2}}-\frac{p_{2}}{q_{2}}
\end{aligned}
$$

and, assuming a zero marginal cost, the second-stage profits $\pi_{i}$ are given by

$$
\begin{aligned}
& \pi_{1}=\left(1-\frac{p_{1}-p_{2}}{q_{1}-q_{2}}\right)\left(p_{1}+s\right) \\
& \pi_{2}=\left(\frac{p_{1}-p_{2}}{q_{1}-q_{2}}-\frac{p_{2}}{q_{2}}\right)\left(p_{2}+s\right) .
\end{aligned}
$$

\footnotetext{
${ }^{3}$ On this point see Kaiser (2006).

${ }^{4}$ When the quality $q_{2}$ of newspaper 2 and its price $p_{2}$ are simultaneously equal to 0 the utility of buying newspaper 2 is equal to the utility of the outside option which is itself equal to 0 . In this case we assume that readers opt for getting newspaper 2. This specification has some importance because it corresponds to the case of a free newspaper of minimum quality. An alternative formulation of the model would consist in setting the minimum quality at a strictly positive level. However it considerably complicates the algebraic treatment of the model without providing any further insight.

${ }^{5}$ Since readers single-home each newspaper acts as a monopolist in the advertisers' market; this can be shown as an equilibrium outcome in a model in which the advertising market is explicitly described and advertisers are allowed to multi-home (see. Gabszewicz, Laussel and Sonnac (2002)).
} 


\section{Equilibrium prices}

From the first order necessary and sufficient conditions, it is straightforward to derive the second-stage Nash equilibrium prices as

$$
\begin{aligned}
& p_{1}=\frac{2 q_{1}\left(q_{1}-q_{2}\right)-3 s q_{1}}{4 q_{1}-q_{2}} \\
& p_{2}=\frac{q_{2}\left(q_{1}-q_{2}\right)-s\left(2 q_{1}+q_{2}\right)}{4 q_{1}-q_{2}}
\end{aligned}
$$

iff $s \leq \frac{q_{2}\left(q_{1}-q_{2}\right)}{\left(2 q_{1}+q_{2}\right)}$. This condition is necessary and sufficient for $p_{2}$ in (1) to be positive. It is sufficient to guarantee that $p_{1}>0^{6}$. The corresponding equilibrium profits are given by

$$
\begin{aligned}
& \pi_{1}=\left(\frac{s+2 q_{1}}{4 q_{1}-q_{2}}\right)^{2}\left(q_{1}-q_{2}\right) \\
& \pi_{2}=\left(\frac{2 s+q_{2}}{4 q_{1}-q_{2}}\right) \frac{q_{2}\left(q_{1}-q_{2}\right)}{q_{1}}
\end{aligned}
$$

For $s \in\left[\frac{q_{2}\left(q_{1}-q_{2}\right)}{\left(2 q_{1}+q_{2}\right)}, q_{1}-q_{2}\right]$, we obtain

$$
\begin{aligned}
& p_{1}=\frac{q_{1}-q_{2}-s}{2} \\
& p_{2}=0,
\end{aligned}
$$

with corresponding equilibrium profits

$$
\begin{aligned}
& \pi_{1}=\frac{\left(s+q_{1}-q_{2}\right)^{2}}{4\left(q_{1}-q_{2}\right)} \\
& \pi_{2}=\frac{s\left(q_{1}-q_{2}-s\right)}{2\left(q_{1}-q_{2}\right)}
\end{aligned}
$$

and, finally, $p_{1}=p_{2}=0$ when $s \geq q_{1}-q_{2}$ with profits $\pi_{1}=s$ and $\pi_{2}=0$.

It is interesting to notice that, for given qualities $q_{1}$ and $q_{2}$, the equilibrium prices of the two newspapers are decreasing in the advertising revenue per reader $s$. However there is not a full pass-through of advertising revenues into lower newspapers prices. Indeed the total receipts per reader $p_{i}+s, i=1,2$, are increasing in $s$ whereas they should be constant in the case of a full pass-through.

${ }^{6}$ Indeed $q_{1}>q_{2} \Longrightarrow s \leq \frac{q_{2}\left(q_{1}-q_{2}\right)}{\left(2 q_{1}+q_{2}\right)}<\frac{1}{3}\left(q_{1}-q_{2}\right) \Longrightarrow p_{1}>0$. 


\section{Equilibrium qualities}

Differentiating $\pi_{1}$ with respect to $q_{1}$ we obtain when $q_{2} \leq 2 s$

$$
\begin{aligned}
& \frac{\partial \pi_{1}}{\partial q_{1}}=0 \text { for } q_{1} \leq q_{2}+s \\
& \frac{\partial \pi_{1}}{\partial q_{1}}=\frac{\left(q_{1}-q_{2}\right)^{2}-s^{2}}{4\left(q_{1}-q_{2}\right)^{2}} \geq 0^{7} \text { when } q_{2}+s \leq q_{1}
\end{aligned}
$$

It is worthwhile to notice that $q_{2} \leq 2 s \Longrightarrow \frac{q_{2}\left(q_{1}-q_{2}\right)}{\left(2 q_{1}+q_{2}\right)}<s$ for all $q_{1} \geq q_{2}$. When $q_{2}>2 s$ we then obtain

$$
\begin{aligned}
& \frac{\partial \pi_{1}}{\partial q_{1}}=0 \text { for } q_{1} \leq q_{2}+s \\
& \frac{\partial \pi_{1}}{\partial q_{1}}=\frac{\left(q_{1}-q_{2}\right)^{2}-s^{2}}{4\left(q_{1}-q_{2}\right)^{2}} \geq 0 \text { when } q_{2}+s \leq q_{1} \leq \frac{q_{2}\left(s+q_{2}\right)}{q_{2}-2 s} \\
& \frac{\partial \pi_{1}}{\partial q_{1}}=\frac{\left(s+q_{1}\right)\left(2 q_{1}\left(4 q_{1}-3 q_{2}-s\right)+q_{2}\left(7 s+4 q_{2}\right)\right)}{\left(4 q_{1}-q_{2}\right)^{3}}>0, \text { when } q_{1} \geq \frac{q_{2}\left(s+q_{2}\right)}{q_{2}-2 s} .
\end{aligned}
$$

We conclude that the profit of the high quality newspaper 1 is an overall increasing function of its quality on the interval $[0,1]$ when $q_{2}+s<1$. It follows that $q_{1}=1$ is a best reply to any $q_{2} \in[0,1-s)$. Any $q_{1} \in[0,1]$ is a best reply to any $q_{2} \geq 1-s$.

Differentiating $\pi_{2}$ with respect to $q_{2}$ we obtain, for $s \in\left[0, \frac{10-\sqrt{96}}{2} q_{1}\right]$

$$
\begin{aligned}
\frac{\partial \pi_{2}}{\partial q_{2}} & =0 \text { when } q_{2} \geq q_{1}-s \\
\frac{\partial \pi_{2}}{\partial q_{2}} & =-\frac{s^{2}}{2\left(q_{1}-q_{2}\right)^{2}}<0 \text { when } q_{2} \in[0, A] \cup\left[B, q_{1}-s\right] \\
\frac{\partial \pi_{2}}{\partial q_{2}} & =-\frac{q_{1}\left(4 s q_{2}^{2}\left(2 s+q_{2}\right)+q_{1}^{2}\left(4 s^{2}-q_{2}^{2}\right)+q_{1} q_{2}\left(-12 s^{2}+8 s q_{2}+7 q_{2}^{2}\right)\right)}{4\left(q_{1}-q_{2}\right)^{3} q_{2}^{2}} \\
\text { when } s & \in[A, B],
\end{aligned}
$$

where $A=\frac{q_{1}-s-\sqrt{q_{1}^{2}+s^{2}-10 s q_{1}}}{2}$ and $B=\left[\frac{q_{1}-s+\sqrt{q_{1}^{2}+s^{2}-10 s q_{1}}}{2}\right.$. Notice that $[A, B] \neq \emptyset$ iff $s \in\left[0, \frac{10-\sqrt{96}}{2} q_{1}\right)$.

On the other hand, for $s \in\left[\frac{10-\sqrt{96}}{2} q_{1}, q_{1}\right]$, we get

$$
\begin{aligned}
& \frac{\partial \pi_{2}}{\partial q_{2}}=0 \text { when } q_{2} \geq q_{1}-s \\
& \frac{\partial \pi_{2}}{\partial q_{2}}=-\frac{s^{2}}{2\left(q_{1}-q_{2}\right)^{2}}<0 \text { when } q_{2} \in\left[0, q_{1}-s\right] .
\end{aligned}
$$




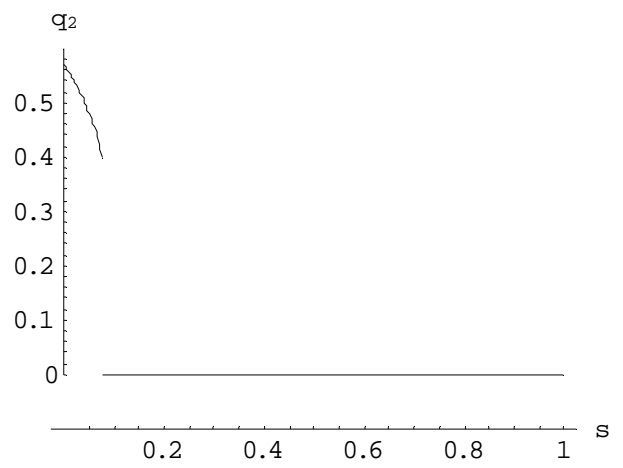

Figure 1: $q_{2}$ as a function of $s$

Proposition 1 There exists a critical level of the revenue per reader for which the low-quality newspaper's editor chooses at equilibrium to provide the lowest possible quality newspaper and sells it at a zero price. More precisely, if $s \in$ $\left[\frac{1}{13}, 1\right]$ then $q_{2}^{*}=p_{2}^{*}=0$.

In fact, it is easy to provide a more complete description of the subgame perfect equilibria of the two stage game described above, as a function of the advertising revenue per reader, which is provided in the following statement. (i) If $s \in\left[0, \frac{1}{13}\right], \quad$ then $q_{1}^{*}=1, \quad q_{2}^{*}=\frac{3 s+2+\sqrt{4-23 s^{2}-44 s}}{4 s+7} \Longrightarrow p_{1}^{*}=$ $\frac{19 s+12 s^{2}-10+2 \sqrt{4-23 s^{2}-44 s}}{-26-13 s+\sqrt{4-23 s^{2}-44 s}}$; (ii) if $s \in\left[\frac{1}{13}, 1\right]$ then $q_{2}^{*}=p_{2}^{*}=0, q_{1}^{*}=1, p_{1}^{*}=\frac{1-s}{2}$. Proof. see Appendix.

Proposition 1 shows that when advertising income per reader increases from 0 the quality of the low quality newspaper decreases until $s$ reaches $\frac{1}{13}$ and then jumps down discontinuously toward the minimum quality (see Figure 1 below) while, simultaneously, it begins to be freely distributed to its readers.

The behavior of the price $p_{1}$ of the high quality journal as the advertising revenue per reader increases is surprisingly non-monotonic (see figure 3 ). As $s$ rises from $0^{8}$ the price $p_{1}$ first decreases slowly, takes a minimum value at $s=\frac{1}{23}(13 \sqrt{3}-22)(\simeq 0.0224635)$ and then rises until $s$ reaches its critical value of $\frac{1}{13}$. At this point $p_{1}$ jumps upward discontinuously from $\frac{7}{26}$ toward $\frac{12}{26}$ and then decreases steadily as $s$ continues to increase. This enlightens somehow the nature of the quality choice of the low-quality newspaper's editor who chooses, when $s$ reaches its critical value, to select the minimum quality level in order to elicit a corresponding discontinuous price increase from the high quality firm.

The intuition behind the choice of quality $q_{2}$ is finally a simple one. the increase in advertising revenue per reader induces the low quality editor to relax

\footnotetext{
${ }^{8} p_{1}(0)=\frac{1}{4}$
} 


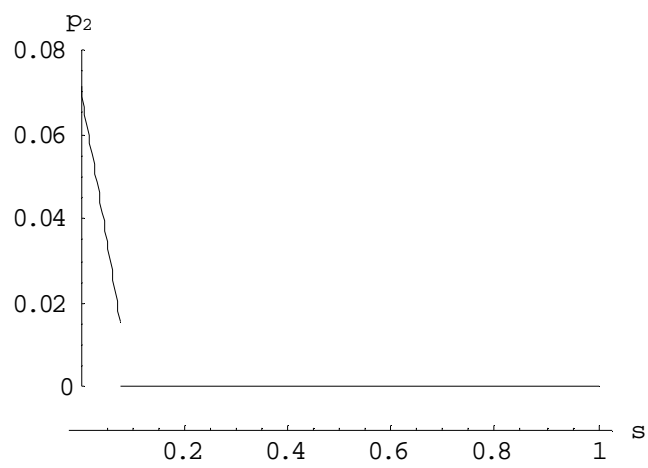

Figure 2: $p_{2}$ as a function of $s$

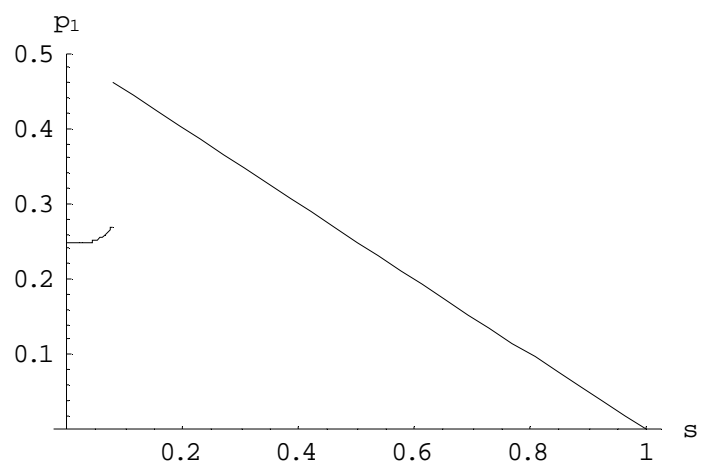

Figure 3: $p_{1}$ as a function of $s$ 

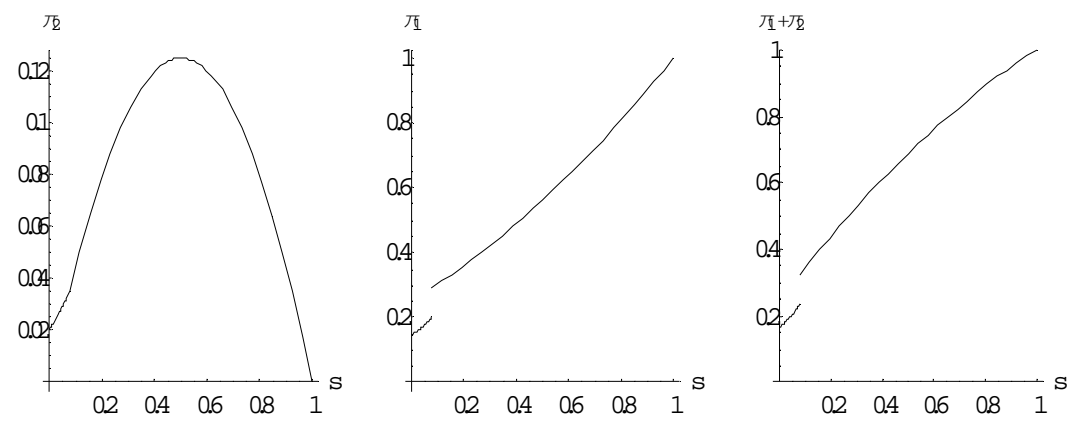

Figure 4: Variation of newspapers' profits with $s$

competition by eliciting price increases of its competitor through its own quality decrease. Since readers are more and more valuable as $s$ increases, gaining more readers with a low preference for quality becomes the primary objective of the newspaper 2's editor.

\section{Profits, Consumers Surplus and Welfare}

Newspapers' profits are globally increasing with $s$, indicating that the additional benefits derived from the advertising market are not (fully) passed on to the readers. Moreover the introduction of minimum quality- free newspapers induces an upward jump in firms' profits which is due to the sudden increase in the price of the high quality journal. Notice that it is the traditional newspaper sold at a positive price which most benefits from higher advertising receipts per reader: its profits monotonically increase with $\mathrm{s}$ with an upward jump at the critical value. Profits of free newspapers first increase and then decrease with $s$ (see figure 4).

The variation of consumers surplus when advertising revenue per reader increases is depicted in Figure 5. It is globally decreasing with $s$ with a downward jump at the point where the low quality newspaper becomes a free (minimum quality) one. This is easily explained by the decrease in the quality of newspaper 2 together with the jump of the price of newspaper 1 at the discontinuity point..

It is obvious from a simple comparison of Figures 4 and 5 above that the money which is poured by the increase in the advertising revenue per reader does not globally benefit to the readers but rather to the newspapers' editors and specifically to the high quality one.

\section{Conclusion}




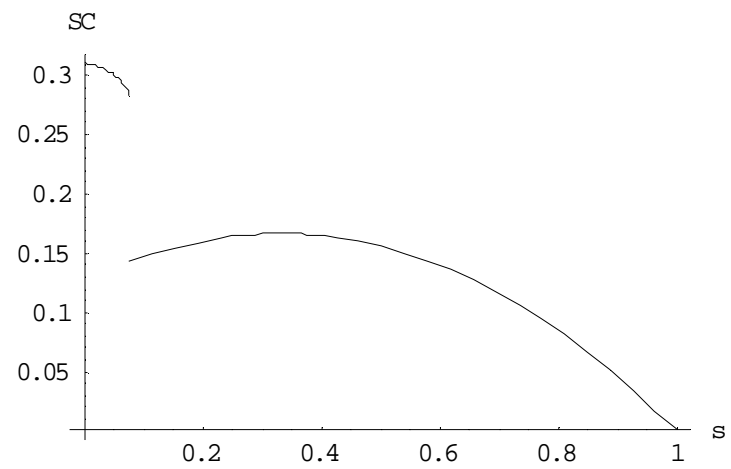

Figure 5: Variation of readers' surplus with $s$

In this paper we have obtained an endogenous explanation for the existence of free newspapers cohabiting with traditional ones as resulting from growing advertising revenues per reader. Beyond a given threshold value, this increase leads to a discontinuous decrease in the price and quality of the low quality newspaper and simultaneously to an increase of the price of the high quality one. Furthermore, this is unambiguously detrimental to the readers. As usual, these conclusions should be taken with the usual caveat imposed by a theoretical capture of real life phenomena : only a restricted domain of these are taken into account by our model. Nonetheless, our approach provides a significant insight to explain the recent growth of the free daily press, which seems to upset the media landscape in several countries.

\section{Appendix}

\section{Proof of Proposition 1:}

Whenever $s \in(0,1)$ there always exist neighborhoods of 0 and $q_{1}-s$ respectively where $\pi_{2}$ is strictly decreasing in $q_{2}$ (see (7) and (9). above). When $s \in\left[\frac{10-\sqrt{96}}{2} q_{1}, q_{1}\right]$ we know that $\pi_{2}$ is strictly decreasing in $q_{2}$ on the whole open interval $\left(0, q_{1}-s\right)$ and then equal to 0 , so that it takes its maximum value at $q_{2}=0$. When $s \in\left[0, \frac{10-\sqrt{96}}{2} q_{1}\right]$ it is easy to check that, when $s \leq \frac{1}{23} q_{1}, \pi_{2}$ (as defined in (2) ) takes its maximum value on $[A, B]$ at an interior point of this non-empty interval, namely $q_{2}^{I}=\frac{3 s q_{1}+2 q_{1}^{2}+\sqrt{4 q_{1}^{4}-23 s^{2} q_{1}^{2}-44 s q_{1}^{3}}}{4 s+7 q_{1}}$.

Though $\pi_{2}$ is discontinuous at $A$ and $B$ there are clearly in this case only two candidate best replies to any $q_{1}>s$ which are $q_{2}=0$ and $q_{2}=q_{2}^{I}$. Since these two values are $<1-s$ the unique best reply by firm 1 to either of them is $q_{1}=1$. Replacing $q_{1}$ by 1 and comparing firm 2's profits at $q_{2}=0$ and 


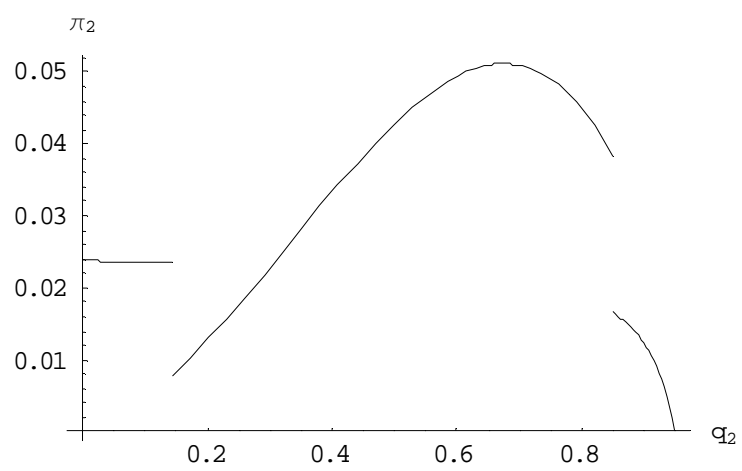

Figure 6: $\pi_{2}$ as a function of $q_{2}(s=0.05)$

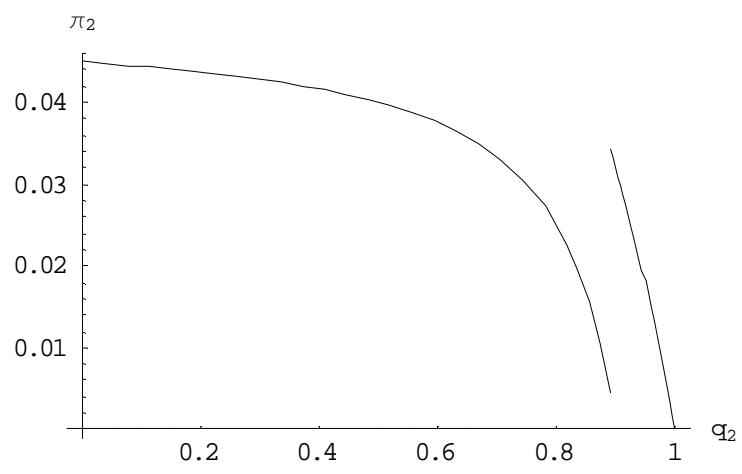

Figure 7: $\pi_{2}$ as a function of $q_{2}(s=0.1)$

$q_{2}=q_{2}^{I}$ it is straightforward to see that $\pi_{2}\left(q_{2}^{I}, s\right)>($ resp. $<) \pi_{2}(0, s)$ if $s<$ (resp. $>) \frac{1}{13}$. Of course $\pi_{2}\left(q_{2}^{I}, \frac{1}{13}\right)=\pi_{2}\left(0, \frac{1}{13}\right)$. Finally it is easy to check that $\frac{1}{13}<\frac{10-\sqrt{96}}{2}$ and $\frac{1}{13}<\frac{2}{23}$.

When . $s>\frac{2}{23} q_{1}$ (but $s<\frac{10-\sqrt{96}}{2} q_{1}$ so that $[A, B]$ is non empty) we see from (2) that $\pi_{2}$ is a decreasing function of $q_{2}$ on $[A, B]$. The only two candidate best replies to any $q_{1}>s$ are now $q_{2}=0$ and $q_{2}=A$. One can check that $q_{2}=0$ always yields a higher profit to firm 2 . Since this value is strictly smaller than $1-s$ the unique best reply by firm 1 is $q_{1}=1$. Figure 7 illustrates this case. 


\section{References}

[1] Anderson S. and S. Coate (2006), Market provision of broadcasting: a welfare analysis, Review of Economic studies 72, 947-972

[2] Dukes A. and E. Gal-Or (2003), Minimum differentiation in commercial media market, Journal of Economics and Management Strategy 12, 291325

[3] Gabszewicz J.J., Laussel D. and N. Sonnac (2001), Press advertising and the ascent of the "Pensée Unique", European Economic Review, 241-251

[4] Gabszewicz J.J., Laussel D. and N. Sonnac (2002), Press advertising and the political differentiation of newspapers, Journal of Public Economic Theory $4,249-259$

[5] Gabszewicz J.J. and J. Thisse (1979), Price competition, quality and income disparities, Journal of Economic Theory 20, 340-359

[6] Kaiser U. (2006), Magazine readers: ad-lovers, ad-haters or ad-neutrals ?, forthcoming in Economics Letters 
Département des Sciences Économiques de l'Université catholique de Louvain

Institut de Recherches Économiques et Sociales

Place Montesquieu, 3

1348 Louvain-la-Neuve, Belgique 